University of South Carolina

Scholar Commons

$1-2007$

\title{
Change in Physical Activity Participation Among Adolescent Girls from 8th to 12th Grade
}

\author{
Russell R. Pate \\ University of South Carolina - Columbia, rpate@mailbox.sc.edu \\ Marsha Dowda \\ University of South Carolina - Columbia, mdowda@mailbox.sc.edu \\ Jennifer R. O'Neill \\ Dianne S. Ward
}

Follow this and additional works at: https://scholarcommons.sc.edu/

sph_physical_activity_public_health_facpub

Part of the Public Health Commons

\section{Publication Info}

Published in Journal of Physical Activity and Health, Volume 4, Issue 1, 2007, pages 3-16.

Pate, R. R., Dowda, M., O'Neill, J. R., \& Ward, D. S. (2007). Change in physical activity participation among adolescent girls from 8th to 12th grade. Journal of Physical Activity and Health, 4(1), 3-16.

(c) Journal of Physical Activity and Health, 2007, Human Kinetics

This Article is brought to you by the Physical Activity and Public Health at Scholar Commons. It has been accepted for inclusion in Faculty Publications by an authorized administrator of Scholar Commons. For more information, please contact digres@mailbox.sc.edu. 


\title{
ORIGINAL RESEARCH
}

Journal of Physical Activity and Health, 2007, 4, 3-16

(C) 2007 Human Kinetics, Inc.

\section{Change in Physical Activity Participation Among Adolescent Girls from 8th to 12th Grade}

\author{
Russell R. Pate, Marsha Dowda, Jennifer R. O’Neill, \\ and Dianne S. Ward
}

\begin{abstract}
Background: Physical activity levels of girls decline in adolescence, but little is known about changes in participation in specific types of physical activity. This study examined change in participation in specific activities during adolescence in girls. Methods: Girls $(N=398$, age $13.6 \pm 0.6$ y at baseline, $58.5 \%$ African American) from 31 middle and 24 high schools in South Carolina completed the 3-Day Physical Activity Recall (3DPAR) in 8th, 9th, and 12th grades. Girls reported their predominant activity and its intensity level in each 30-min time block on the previous 3 d. Results: Vigorous physical activity declined from $45.4 \%$ in 8 th grade to $34.1 \%$ in 12 th grade. The probability of participating in several forms of vigorous physical activity in 12 th grade was strongly associated with participation in those activities in 8th grade. Conclusion: Early-in-life participation in sports and other forms of vigorous physical activity are important to the maintenance of physical activity during adolescence in girls.
\end{abstract}

Key Words: African American, longitudinal, sports, employment, transportation

Physical activity provides important health benefits to adolescents, ${ }^{1,2}$ and promotion of physical activity in youth has become a key public health objective ${ }^{3}$ in the US and other developed countries. ${ }^{4,5}$ Previous research has demonstrated consistently that physical activity levels decline with increasing age and tend to be lower in girls than boys. ${ }^{1,6,7}$ The National Growth and Health Study observed that physical activity levels declined by $83 \%$ in girls between the ages of 9 and $19 .{ }^{6}$ Furthermore, African American girls have lower physical activity levels than white girls. ${ }^{6.8}$ These findings point to the need to fully understand how and why girls' physical activity changes during adolescence.

Physical activity guidelines for youth typically have been presented in terms of a recommended daily number of minutes of moderate-to-vigorous intensity activity. For example, the prevailing guideline calls for youth to engage in at least $60 \mathrm{~min}$

Pate, Dowda, and O'Neill are with the Dept of Exercise Science, Arnold School of Public Health, University of South Carolina, Columbia, SC 29208. Ward is with the Dept of Nutrition, School of Public Health, University of North Carolina, Chapel Hill, NC 27599. 
of moderate-to-vigorous physical activity daily. ${ }^{1,2,9,10}$ Such a focus on cumulative minutes of activity is appropriate in physiologic terms, since the health benefits of physical activity are most closely associated with chronic physical activity energy expenditure. ${ }^{1,11}$ However, a person's physical activity behavior is a function of the specific types of physical activity in which he/she chooses to engage. Accordingly, efforts to promote increased physical activity in youth are informed by a knowledge of the specific types of physical activity in which they engage.

Most previous studies examining change in physical activity during adolescence have focused on measures of total physical activity. ${ }^{6,12,13}$ Only a small number of studies have reported on change in participation in specific types of activity, ${ }^{14-16}$ and those studies have been limited by the use of instruments that called for youth to report only the most common forms of physical activity. For example, two studies required youth to select recreational activities they performed from a list, ${ }^{14,16}$ while another collected the three most common activities performed. ${ }^{15}$ There is also limited information about differences in changes of activities among African American and white girls. ${ }^{17}$ The present study was designed to examine, in a comprehensive way, change in participation in specific sedentary and physical activities during adolescence in African American and white girls. Because many older adolescent girls have part-time jobs, we included an examination of change in work-related physical activity during the high school years.

\section{Methods}

\section{Study Design and Participants}

The present investigation reports longitudinal analyses of data that were collected as part of the measurement protocol in a large school-based physical activity intervention study. Participants were 8th, 9th, and 12th grade girls who were students in 31 middle schools and 24 high schools in South Carolina. All girls in the participating schools were invited to participate. Eighth grade girls were recruited in the spring of 1998 and the spring of 1999. Overall, 2744 girls (average age $13.6 \pm 0.6 \mathrm{y} ; 49.0 \%$ African American) completed the measurement protocol in 8th grade. The same girls were invited to complete the protocol again in 9th and 12th grades. Ninth grade girls were recruited in the spring of 1999 and 2000 and 12th grade girls in the spring of 2002 and 2003. The study reported in this article is based on the 398 girls (58.4\% African American, $41.6 \%$ white) who provided complete data on physical activity at the 8 th, 9 th, and 12 th grade time points. The study group is similar to the 2744 girls who were measured in 8th grade with regard to age $(13.6 \pm 0.6 ; 13.6 \pm 0.6)$, body-mass index $(23.1 \pm 5.7$; $23.6 \pm 5.6)$, percentage from the control group $(46.2 \% ; 44.5 \%)$, and participation in two or more blocks of MVPA $(72.4 \% ; 71.1 \%)$ and one or more blocks of VPA $(45.0 \% ; 42.3 \%)$, respectively. The study group had a slightly higher percentage of African American girls (58.4\%) compared to the initial sample (49.0\%). Written informed consent was obtained from each girl and her primary guardian prior to collection of any data. The study was approved by the University of South Carolina Institutional Review Board. 


\section{Physical Activity Recall}

The 3-Day Physical Activity Recall (3DPAR) was used to measure participation in physical activity and other activities. This instrument is a modification of the Previous Day Physical Activity Recall (PDPAR), which previous studies have shown to be valid and reliable. ${ }^{18,19}$ The 3DPAR has been validated against accelerometry in 8th and 9th grade girls. ${ }^{20}$ The 3 DPAR uses a script and graphic figures to explain the intensity level of common activities. Light activities are described as requiring little or no movement with slow breathing, moderate activities as requiring some movement and normal breathing, hard activities as requiring moderate movement and increased breathing, and very hard activities as requiring quick movements and hard breathing.

The 3DPAR was administered to the participants in the spring of their 8th, 9th, and 12th grade years by trained research assistants. The instrument was always administered on a Wednesday, with participants asked to recall their activities on the previous $3 \mathrm{~d}$ (first Tuesday, then Monday, then Sunday). Participants were asked to complete a grid for each day recalled. The grid was divided into 30-min time blocks, beginning at $7 \mathrm{AM}$ and ending at 12 midnight. Participants were asked to report their predominant activity in each of the 30-min blocks. A list of 55 activities was provided that included sedentary activities, activities of daily living, physical activities, physical education, and sports. Participants were asked to enter the number of an activity and to indicate if the activity was performed at a light, moderate, hard or very hard intensity. The 3DPAR includes a rating of intensity because many activities can be performed at varying intensities, and we have previously shown that including an intensity rating for each reported activity enhances the validity of this instrument. ${ }^{19}$

\section{Physical Activity Participation}

Data from each day were reduced to the number of 30-min blocks for which the reported activity was rated at an intensity of $3 \mathrm{METs}$ or more (moderate-to-vigorous physical activity, MVPA) and 6 METs or more (vigorous physical activity, VPA). MET values for each activity were obtained from the Compendium of Physical Activities. ${ }^{21}$ Girls were classified as meeting physical activity standards if they reported an average of two or more 30-min blocks of MVPA per day, and/or one or more 30-min blocks of VPA per day.

For this study, a girl was considered a participant in a specific activity if she reported engaging in that activity on at least one of the three days assessed by the 3DPAR. For each activity, the mean number of 30-min blocks for each participant was calculated by dividing the number of reported 30-min blocks by the number of days on which the activity was performed to produce the frequency of 30min blocks/day. For this analysis the activities were grouped into categories: all sedentary activities, leisure time sedentary activities, (e.g., television, computer), educational sedentary activities (e.g., reading, homework), physical education, other school activities (e.g., band, clubs), sedentary school activities (e.g., classes, lunch), team sport activities (e.g., basketball, soccer), individual physical activities (e.g., aerobics, dance), lifestyle physical activities (e.g., chores, shopping), job, church, travel by car or bus, eat, dress/get ready/sleep, and other activity. 


\section{Potential Confounders}

All analyses were adjusted for body-mass index (BMI) and socioeconomic status because previous studies have reported differences in physical activity by BMI and socioeconomic status. ${ }^{22}$ Height was measured to the nearest $1.0 \mathrm{~cm}$ with a portable stadiometer and weight was measured to the nearest $0.1 \mathrm{~kg}$ with a digital scale. Body-mass index (BMI) was calculated by dividing weight in kilograms by height in meters squared. Parent education was the indicator of socioeconomic status (SES). Highest parent education reported by the girl was dichotomized into high school education or less and greater than high school education.

\section{Statistical Analyses}

Because the girls were from 31 middle schools and 24 high schools and girls in a particular school share a unique social and physical environment, it was important that the statistical analysis control for the influence of school. Accordingly, school was treated as a random effect in all analyses. To summarize the data, SAS was used to compute descriptive statistics (means, standard deviations, and frequencies). ${ }^{23}$ The prevalence of participation in an average of two or more 30 -min blocks of MVPA per day and one or more 30-min blocks of VPA per day during the 3-d period was examined for the total sample and by race (white, African American). Repeated measure 2-way ANOVA [time (8th, 9th, 12th grade) $\times$ race] was performed using Proc Mixed, with school as a random effect, while controlling for group (control/intervention), 12th grade BMI, and SES).

The mean activity in each category is the average number of reported 30 -min blocks of the combined activities at each time point. Repeated measure 2-way ANOVA (time $\times$ race) using proc mixed was performed, with school as a random effect, while controlling for group, 12th grade BMI, and SES. This same procedure was used to determine the prevalence of participation for selected sports team and individual activities.

To examine the probability of girls continuing selected activities from the 8th to 9 th grade and the 8 th to 12 th grade, logistic analyses were performed using the PROC GLIMMIX logit link and binomial error distribution. ${ }^{24}$ Odds ratios and $95 \%$ confidence intervals were reported. This was done using 8th grade as the independent variable to predict both 9 th and 12 th grade participation.

\section{Results}

Mean age of the 8th grade girls was 13.6 (standard deviation $=0.6$ ) y, and $46.2 \%$ of the girls were from control schools. Over $70 \%$ of the 8th grade girls reported an average of two or more blocks of MVPA per day, and $45 \%$ of the girls reported an average of one or more blocks of VPA per day. At the 12th grade measure, African American girls had higher BMIs than white girls $($ mean $=26.2$, standard deviation $=$ 6.8 vs. mean $=24.2$, standard deviation $=5.9, P=0.002$ ). Fewer African American girls than white girls had a parent with greater than a high school education $(55.8 \%$ vs. $72.1 \%, P=0.001)$.

The prevalence of participation in two or more blocks of MVPA per day and one or more blocks of VPA per day and the mean number of 30-min blocks of 
MVPA and VPA at each time point is presented in Table 1. Overall, fewer African American girls participated in MVPA and VPA than white girls. From 8th to 9th grade, the prevalence of meeting the MVPA standard decreased in white girls and increased slightly in African American girls, whereas the prevalence of meeting the VPA standard decreased for both groups. The mean number of 30-min blocks of MVPA increased from 8th to 12th grade in both African American and white girls, with a greater increase among the African American girls. The mean number of 30-min blocks of VPA also increased from 8th to 12th grade among African American girls, however, only slightly.

The mean number of 30-min blocks per day of participation in specific activities by category at each time point is presented in Table 2. Participation in team sport activities decreased only in white girls and individual physical activities decreased over time for both white and African American girls. All sedentary activities, including both leisure time sedentary activities $(P<0.01)$ and educational sedentary activities $(P=0.09)$ decreased from 8 th grade to 12 th grade. Job activity, however, increased. In 8th grade, the mean number of 30-min blocks at work was 0.1 blocks; in 12 th grade it was 3.2 blocks. Travel by car or bus and other activities also increased significantly from 8 th to 12 th grade.

The prevalence of participation in selected team sport activities and individual physical activities is shown in Table 3 . The percentage of girls participating in basketball, softball/baseball, dancing (ballet, jazz, modern, tap), and jogging/running decreased significantly from 8th to 12 th grade in both white and African American girls. Compared to African American girls, more white girls reported participating in calisthenics and soccer at each time point. However, there was no significant decrease in participation over time for either group for these activities. Travel by walking also decreased significantly from 8th to 12th grade in both groups of girls although more African American girls reported travel by walking. The probabilities of girls continuing those selected activities from the 8th to 9th grade and the 8 th to 12 th grade are presented in Table 4. Overall, most of the odds ratios were significant; girls who participated in activities in 8th grade were more likely to participate in the same activities in 9th and 12th grade, compared to girls who did not participate in those activities in 8 th grade.

\section{Discussion}

Changes in overall physical activity and specific physical activity behaviors were monitored in a cohort of nearly 400 girls between the 8th and 12th grades. A key finding was that the percentage of girls meeting a vigorous physical activity standard declined from $45.4 \%$ in the 8 th grade to $34.1 \%$ in the 12 th grade. This decline in vigorous physical activity was explained by age-related decreases in participation in team sport and individual physical activities. Decreases in participation in basketball, bicycling, running, soccer, and softball were particularly pronounced. Importantly, it was observed that the probability of participating in several forms of vigorous physical activity in 12th grade was strongly associated with participation in those specific activities in the 8th grade. This observation suggests that early-in-life participation in sports and other forms of physical activity is important to the maintenance of physical activity during adolescence in girls. 


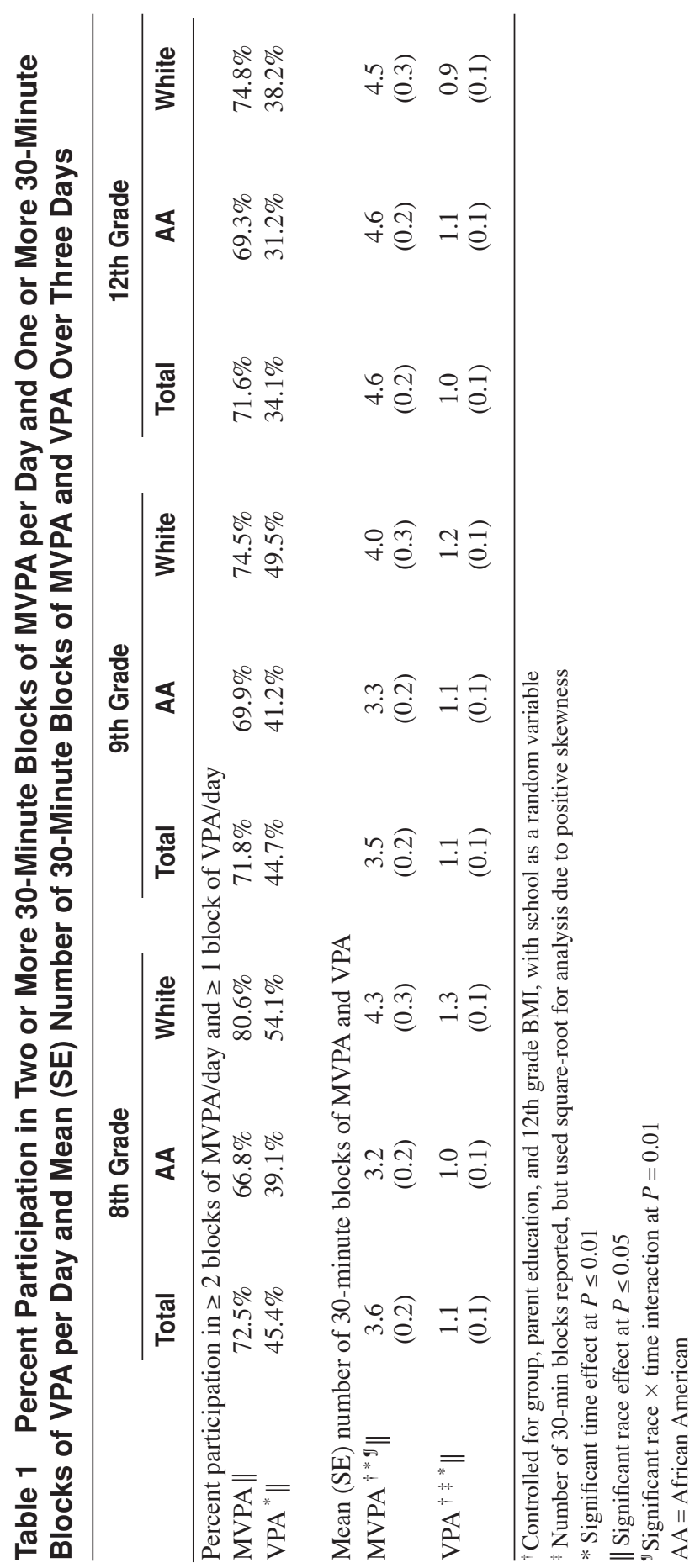




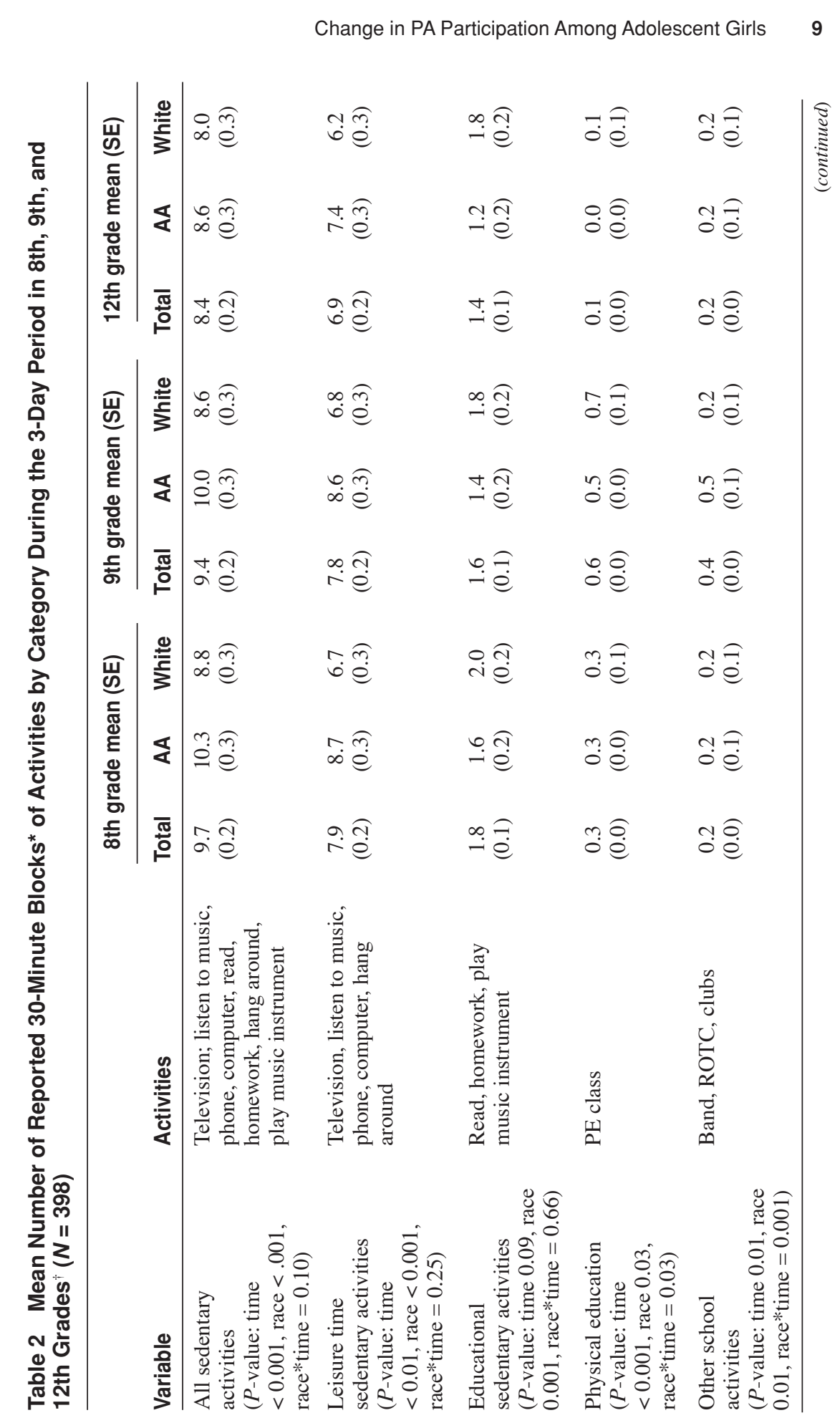




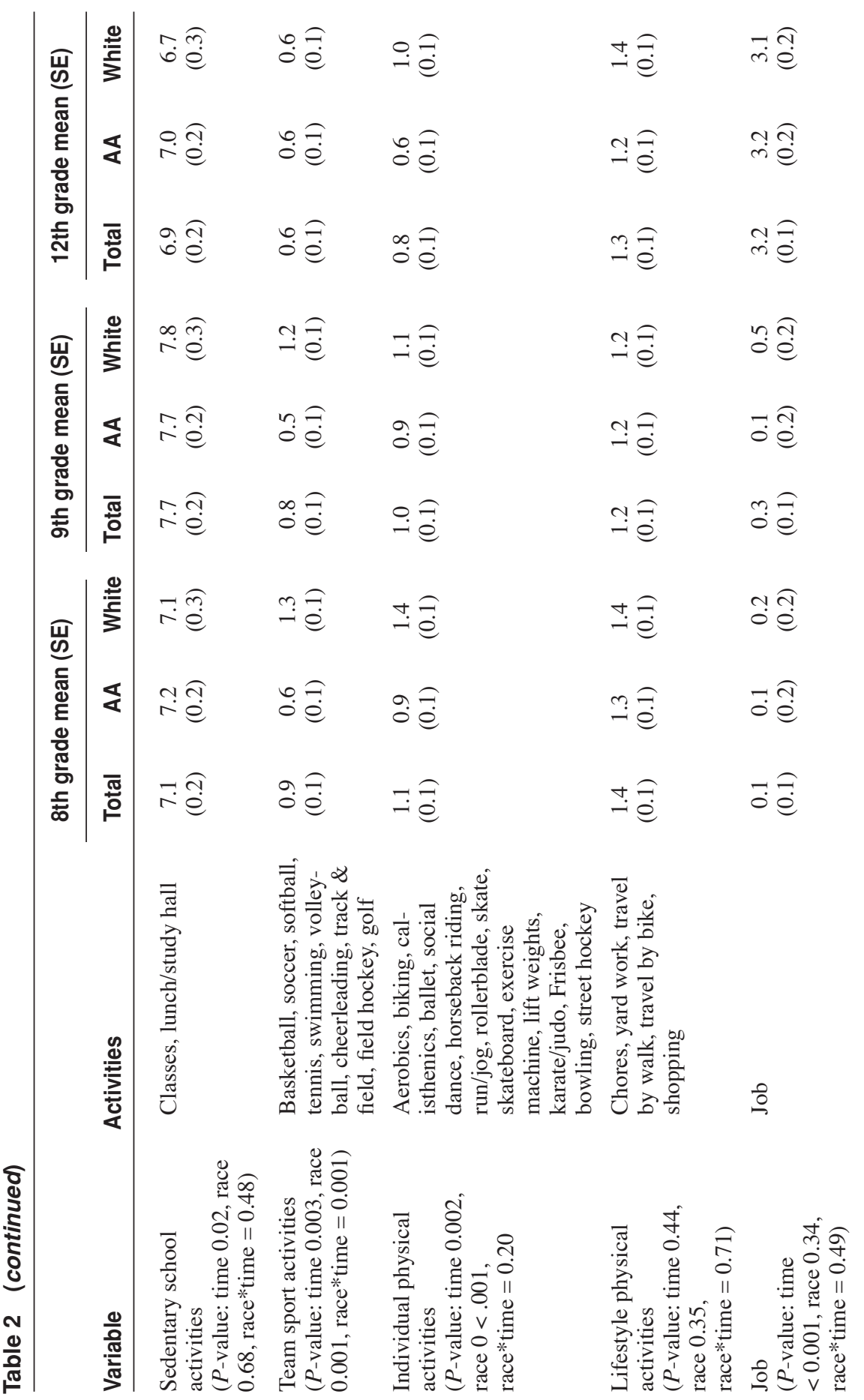




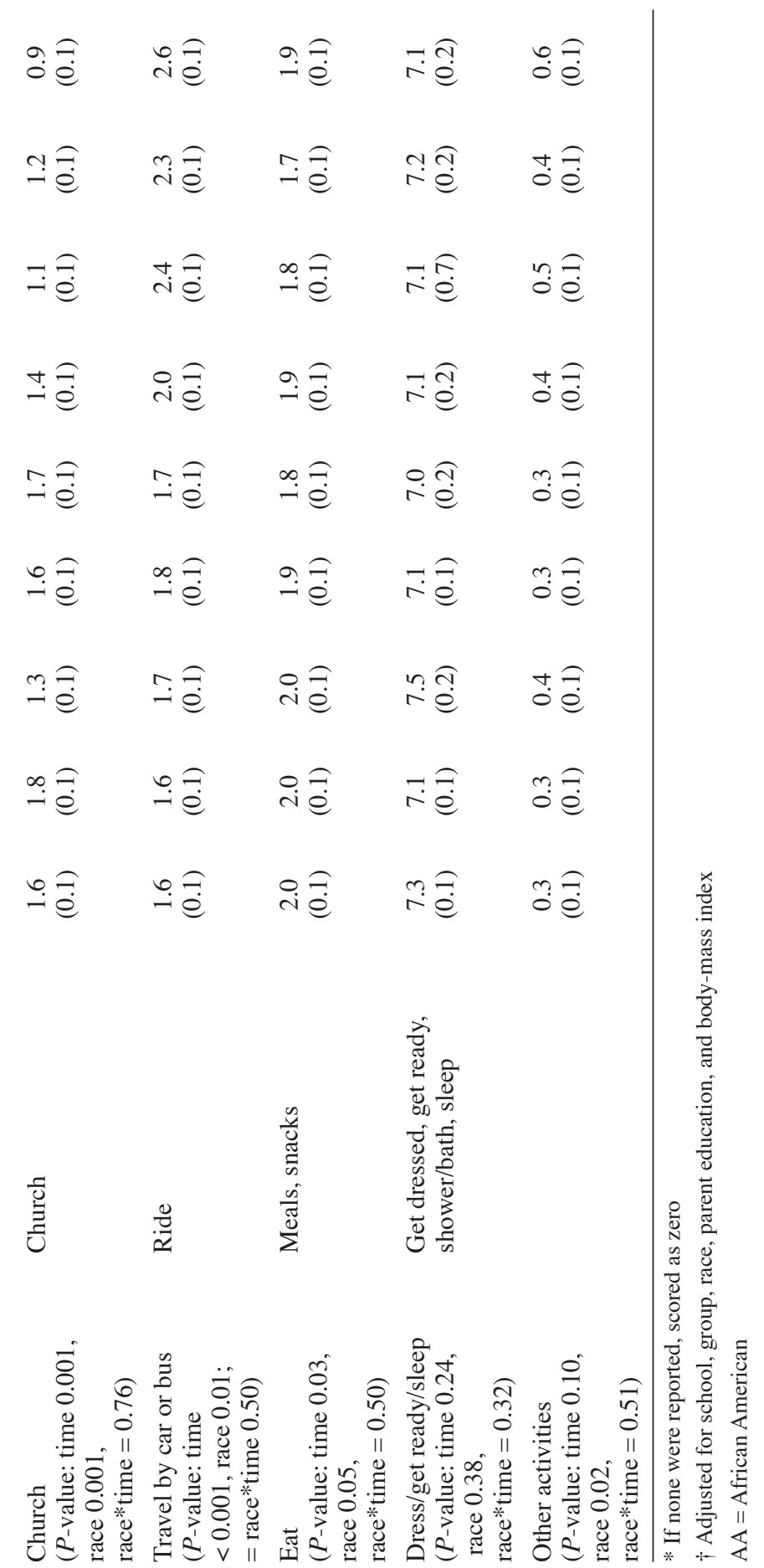




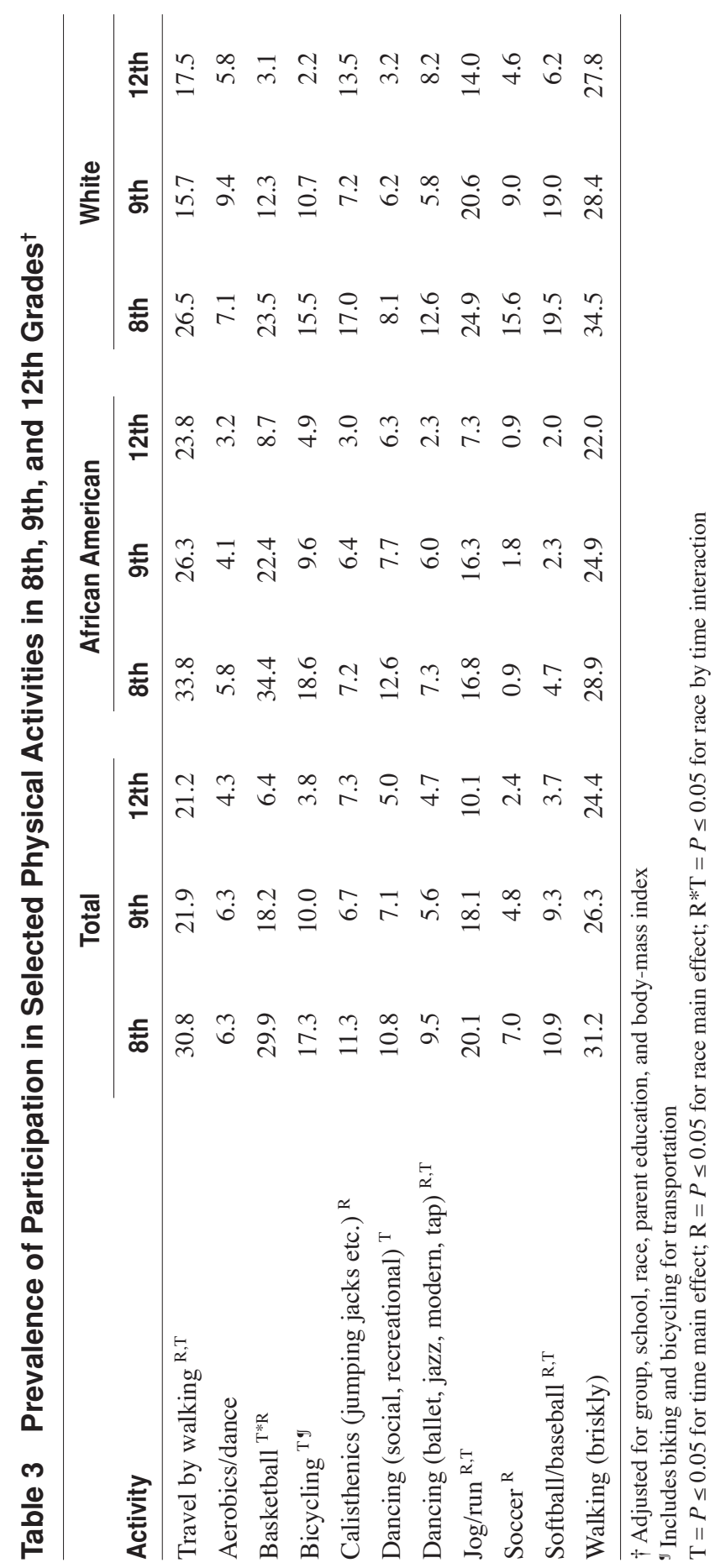


Table 4 Odds Ratios Indicating Probability of Girls Participating in Selected Physical Activities in 9th or 12th Grade Based on Participation in 8th Grade ${ }^{\dagger}$

\begin{tabular}{|c|c|c|c|c|}
\hline \multirow[b]{2}{*}{ Activity } & \multicolumn{2}{|c|}{ 8th to 9th grade } & \multicolumn{2}{|c|}{ 8th to 12 th grade } \\
\hline & OR & $95 \% \mathrm{Cl}$ & OR & $95 \% \mathrm{Cl}$ \\
\hline Travel by walking & $2.53 * *$ & $1.48,4.30$ & $2.29 * *$ & $1.33,3.94$ \\
\hline Aerobics/dance & 2.27 & $0.55,9.31$ & 0.77 & $0.08,6.97$ \\
\hline Basketball & $3.47 * * *$ & $1.97,6.12$ & $3.17 *$ & $1.28,7.71$ \\
\hline Bicycling & $7.26 * * *$ & $3.59,14.69$ & $4.15^{*}$ & $1.43,12.10$ \\
\hline Calisthenics & 2.39 & $0.83,6.87$ & 2.12 & $0.77,5.86$ \\
\hline $\begin{array}{l}\text { Dancing (social, } \\
\text { recreational) }\end{array}$ & $4.36 * *$ & $1.70,11.22$ & 2.02 & $0.57,7.24$ \\
\hline $\begin{array}{l}\text { Dancing (ballet, jazz, } \\
\text { modern, tap) }\end{array}$ & $9.46 * *$ & $2.82,31.82$ & $11.20 * * *$ & $3.37,37.27$ \\
\hline Jog/run & $2.84 * *$ & $1.54,5.25$ & $3.77 * *$ & $1.75,8.13$ \\
\hline Soccer & $8.40 * *$ & $2.27,31.08$ & $24.05 * * *$ & $6.23,92.88$ \\
\hline Softball/baseball & $6.38 * * *$ & $2.69,15.15$ & $8.07 * *$ & $2.18,29.86$ \\
\hline Walking (briskly) & 1.52 & $0.91,2.54$ & $2.56 * *$ & $1.53,4.28$ \\
\hline
\end{tabular}

$\dagger$ Adjusted for group, school, race, parent education, and body-mass index

$* \leq 0.05 ; * *<0.01 ; * * *<0.001$

Although many previous studies have examined the change in total physical activity during adolescence, ${ }^{6,12,13}$ very few have examined the change in participation in specific types of activity. ${ }^{14-16}$ Our findings are consistent with the findings of three previous studies. In those studies the decline in physical activity during adolescence ranged from 26 to $37 \% .{ }^{14,16}$ Aaron and colleagues reported that the negative predictive value was high and consistent for boys and girls, meaning that if youth did not participate in activities in middle school, they were unlikely to participate in those activities in high school. ${ }^{16}$ Similarly, among girls, participation in team sports decreased from middle school to high school. ${ }^{15}$ Two of the studies reported a decline in the number of activities with increasing age. ${ }^{14,15}$ Among girls, decreases in specific activities that were comparable to those found in the present study were bicycling, ${ }^{14-16}$ running, ${ }^{14,15}$ dancing, ${ }^{15}$ softball, ${ }^{16}$ and basketball. ${ }^{16}$ The present study and the three previously published studies provide evidence that the age-related decline in physical activity in adolescent girls is associated with decreased participation in bicycling, softball, basketball, dancing, and running. ${ }^{14-16}$

The present study is unique in that it assessed a broader array of activities than were observed in previous longitudinal studies. Motorized transportation tended to replace physically active transportation. Travel by car or bus increased from 9th to 12 th grade, while travel by walking and bicycling decreased. Increased distance to school may be one reason for the decrease in active commuting as girls moved from middle school to high school. ${ }^{25}$ In addition, most of the girls obtained a driver's license (or had friends who did) during that period, and many adolescents enjoy driving around with their friends. Approximately $65 \%$ of high school seniors 
report riding around in a car (or motorcycle) just for fun at least once a week. ${ }^{26}$ Employment also increased from 9th to 12 th grade. Nationally, about $32 \%$ of $16-17$ year-old female high school students are employed, ${ }^{26}$ but the relationship between physical activity and employment is unclear. One study found that employment was a barrier to physical activity among youth, ${ }^{27}$ but another found that employed students were more active and suggested that the money they earn from part-time jobs may allow them to participate in physical activities that they could not afford otherwise. ${ }^{8}$ Additional research is needed to clarify the effects of transportation and employment on physical activity in adolescent girls.

Results from this study confirm previous research findings that participation in sports and other physical activities during early adolescence is linked to continued participation in those specific activities during late adolescence. ${ }^{28}$ Girls, especially African American girls, are at great risk for steep declines in physical activity between childhood and late adolescence. ${ }^{6,8}$ And, in spite of the universal attraction of sport and physical activity to young people, youth sport participation has decreased in recent years, in both the US ${ }^{7,29,30}$ and other countries. ${ }^{31}$ For example, the percentage of American girls that reported playing on one or more sports teams decreased from $53.4 \%$ in 1997 to $50.2 \%$ in $2005 .{ }^{29,30}$ Early exposure to sports and other physical activities, however, can increase the likelihood that young people will engage in those activities over time. In the current study, girls who participated in a sport or physical activity in 8th grade were much more likely than other girls to participate in that sport or activity in 12 th grade.

One resource for increasing and maintaining girls' participation in physical activity during adolescence is school physical education. Physical education classes offer opportunities for adolescent girls to try new sports and activities, learn activity skills, and enjoy physical activity in a safe and controlled environment. A majority of 8th and 9th grade girls take physical education, while a majority of 12th grade girls do not. Therefore, physical educators can provide girls with enjoyable physical activity experiences and teach them skills for being active in early adolescence, increasing the likelihood that they will continue to participate in physical activity in late adolescence and into young adulthood.

This study had a number of strengths, including approximately equal numbers of African American and white girls and inclusion of middle schools and high schools in rural, suburban, and urban areas. In addition, the study measured physical activity at three time points, using the same instrument each time, over the period during adolescence when physical activity in girls typically declines dramatically. Limitations of the study include the smaller total pool of girls available for recruitment in 12th grade, to which the high dropout rate in South Carolina high schools may have contributed. The measure of physical activity was a self-report measure; however, information on the types of activities performed could not be assessed with accelerometry. Additionally, the 3DPAR has been validated against accelerometry and has demonstrated factorial validity and invariance in adolescent girls. ${ }^{20,32}$

In summary, vigorous physical activity among adolescent girls declined from $45.4 \%$ in 8 th grade to $34.1 \%$ in 12 th grade. This decline was explained by age-related decreases in participation in team sport and individual physical activities, particularly basketball, bicycling, running, soccer, and softball. Conversely, employment and motorized transportation increased from 9 th to 12 th grade. The probability of 
participating in several forms of moderate and vigorous physical activity in 12th grade was strongly associated with participation in those specific activities in the 8th grade. These findings indicate the importance of early exposure to sports and other forms of moderate and vigorous physical activity to the maintenance of physical activity during adolescence in girls.

\section{Acknowledgments}

The authors thank Gaye Groover Christmus for editing the manuscript. This study was funded by a grant from the National Institutes of Health (R01HL057775).

\section{References}

1. US Dept of Health and Human Services. Physical Activity and Health: A Report of the Surgeon General. Atlanta: USDHSS/CDC; 1996.

2. Strong WB, Malina RM, Blimkie CJ et al. Evidence based physical activity for schoolage youth. J Pediatr. 2005;146:732-737.

3. US Dept of Health and Human Services. Healthy People 2010 (2nd ed.). Washington: US Govt Printing Office; 2000.

4. European Heart Network EHHI. Children and young people: The importance of physical activity. www.ehnheart.org 2001; Available at: URL: http://www.ehnheart. org/content/ItemPublication.. sp? docid=4522\&level0=1455\&level1=1611. Accessed January 12, 2006.

5. World Health Organization. Global Strategy on Diet, Physical Activity and Health. World Health Organization 2004; Available at: URL: http://www.who.int/dietphysicalactivity/strategy/eb11344/strategy_english_web.pdf. Accessed January 25, 2006.

6. Kimm SY, Glynn NW, Kriska AM et al. Decline in physical activity in black girls and white girls during adolescence. N Engl J Med. 2002;347:709-715.

7. Centers for Disease Control and Prevention. Youth Risk Behavior Surveillance-United States, 2003. MMWR Morb Mortal Wkly Rep. 2004;53 (SS02):1-96.

8. Harris KM, Gordon-Larsen P, Chantala K, Udry JR. Longitudinal trends in race/ethnic disparities in leading health indicators from adolescence to young adulthood. Arch Ped \& Adolesc Med. 2006;160:74-81.

9. US Dept of Agriculture. Nutrition and Your Health: Dietary Guidelines for Americans, 2005 Dietary Guidelines Advisory Committee Report. Washington: USDA; 2004.

10. Cavill N, Biddle S, Sallis JF. Health enhancing physical activity for young people: Statement of the United Kingdom Expert Consensus Conference. Pediatr Exerc Sci. 2001;13:12-25.

11. Pate RR, Pratt M, Blair SN et al. A recommendation from the Centers for Disease Control and Prevention and the American College of Sports Medicine. JAMA. 1995;273:402407.

12. Janz KF, Dawson JD, Mahoney LT. Tracking physical fitness and physical activity from childhood to adolescence: The Muscatine study. Med Sci Sports Exerc. 2000;32:12501257.

13. van Mechelen W, Twisk JW, Post GB, Snel J, Kemper HC. Physical activity of young people: The Amsterdam Longitudinal Growth and Health Study. Med Sci Sports Exerc. 2000;32:1610-1616.

14. Dovey SM, Reeder AI, Chalmers DJ. Continuity and change in sporting and leisure time physical activities during adolescence. Br J Sports Med. 1998;32:53-57.

15. Bradley CB, McMurray RG, Harrell JS, Deng S. Changes in common activities of 3rd through 10th graders: the CHIC study. Med Sci Sports Exerc. 2000;32:2071-2078. 
16. Aaron DJ, Storti KL, Robertson RJ, Kriska AM, Laporte RE. Longitudinal study of the number and choice of leisure time physical activities from mid to late adolescence: implications for school curricula and community recreation programs. Arch Pediatr Adolesc Med. 2002;156:1075-1080.

17. Myers L, Strikmiller MS, Webber L, Berenson GS. Physical and sedentary activity in school children grades 5-8: The Bogalusa Heart Study. Med Sci Sports Exerc. 1996;28:852-859.

18. Trost SG, Ward DS, McGraw B, Pate RR. Validity of the Previous Day Physical Activity Recall (PDPAR) in fifth-grade children. Pediatr Exerc Sci. 1999;11:341-348.

19. Weston AT, Petosa R, Pate RR. Validation of an instrument for measurement of physical activity in youth. Med Sci Sports Exerc. 1997;29:138-143.

20. Pate RR, Ross R, Dowda M, Trost SG, Sirard J. Validation of a three-day physical activity recall instrument in female youth. Pediatr Exerc Sci. 2003;15:257-265.

21. Ainsworth BE, Haskell WL, Whitt MC et al. Compendium of Physical Activities: An update of activity codes and MET intensities. Med Sci Sports Exerc. 2000;32(9 Suppl): S498-S516.

22. Sallis JF, Prochaska JJ, Taylor WC. A review of correlates of physical activity of children and adolescents. Med Sci Sports Exerc. 2000;32:963-975.

23. SAS OnlineDOC, Version 8 with PDF Files. Cary, NC: SAS Institute; 2000.

24. Murray DM. Design and Analysis of Group-Randomized Trials. New York: Oxford University Press; 1998.

25. Centers for Disease Control and Prevention. Barriers to children walking to or from school-United States, 2004. Morb Mortal Wkly Rep. 2005;54:949-952.

26. Fox MA, Connolly BA, Snyder TD. Youth Indicators 2005: Trends in the Well-being of American Youth. Washington: National Center for Education Statistics, US Dept of Education; 2005.

27. Tappe MK, Duda JL, Ehrnwald PM. Perceived barriers to exercise among adolescents. J Sch Health. 1989;59:153-155.

28. Telama R, Yang X, Laakso L, Viikari J. Physical activity in childhood and adolescence as predictor of physical activity in young adulthood. Am J Prev Med. 1997;13:317323.

29. Pate RR, Trost SG, Levin S, Dowda M. Sports participation and health-related behaviors among US youth. Arch Pediatr Adolesc Med. 2000;154:904-911.

30. Centers for Disease Control and Prevention. Youth Risk Behavior Surveillance-United States, 2005. Morb Mortal Wkly Rep. 2006;55(SS05):1-112.

31. Dollman J, Norton K, Norton L. Evidence for secular trends in children's physical activity behaviour. Br J Sports Med. 2005;39:892-897.

32. Motl RW, Dishman RK, Dowda M, Pate RR. Factorial validity and invariance of a self-report measure of physical activity among adolescent girls. Res $Q$ Exerc Sport. 2004;75:259-271. 